\title{
Intellectual property and the African continental free trade area: lessons and recommendations for the IP protocol
}

\author{
Caroline B. Ncube
}

Department of Commercial Law, University of Cape Town, Cape Town, South Africa

\begin{abstract}
Purpose - This paper aims to explore the contours of the future intellectual property (IP) protocol of the African Continental Free Trade Area (AfCFTA) Agreement.

Design/methodology/approach - This paper frames the IP protocol within the architecture of the AfCFTA Agreement, meaning that it will follow the structure of other protocols and will be guided by the Agreement's foundational principles and objectives. With the place, shape and form of the protocol so established, the paper considers the substantive aspects that ought to be addressed. It also considers provisions on technical assistance, capacity building and cooperation.

Findings - The paper finds that the Tripartite Free Trade Phase 2 IP agenda is a credible starting place, which must be broadened to better meet gendered challenges and the continent's developmental priorities. This will entail including provisions on specific aspects enumerated in the paper, which must be aligned with provisions on technical assistance, capacity building and cooperation to enhance implementation. The best outcomes in the negotiation, adoption and implementation of the IP protocol will be achieved by an inclusive approach incorporating all national, sub-regional and regional institutions guided by coherent policy and coordinated to ensure efficiency in resources and capacity mobilisation.
\end{abstract}

Originality/value - To the best of the author's knowledge, this is the first paper to formally consider both the architecture and substantive provisions of the future AfCFTA IP protocol with specific focus on gendered dimensions.

Keywords Intellectual property, Gender, African Continental Free Trade Area (AfCFTA)

Paper type Research paper

(C) Caroline B. Ncube. Published by Emerald Publishing Limited. This article is published under the Creative Commons Attribution (CC BY 4.0) licence. Anyone may reproduce, distribute, translate and create derivative works of this article (for both commercial and non-commercial purposes), subject to full attribution to the original publication and authors. The full terms of this licence may be seen at http://creativecommons.org/licences/by/4.0/legalcode

This work was carried out under the auspices of the SARChI Chair: Intellectual Property, Innovation and Development, University of Cape Town. This work is based on research supported in part by the National Research Foundation (NRF) of South Africa (Grant number: 115716). Any opinion, finding and conclusion or recommendation expressed in this material is that of the author and the NRF does not accept any liability in this regard.

This work also constitutes part of the Open African Innovation Research (OpenAIR) partnership's thematic research. OpenAIR work is carried out with financial support from the International Development Research Centre, Canada, the Social Sciencesand Humanities Research Council of Canada, and Queen Elizabeth Scholarships - Advanced Scholars (QES-AS) through Community Foundations of Canada (CFC). The views expressed herein do not necessarily represent those of Open AIR's funders.

Do

\footnotetext{
Journal of International Trade Law and Policy Vol. 21 No. 2, 2022 pp. 105-121
Emerald Publishing Limited 1477-002 DOI 10.1108/JTTLP-09-2021-0051
} 
JITLP

21,2

\section{Introduction}

Intellectual property (IP) is currently high on the African Union (AU)'s agenda because of its prominence in the African Continental Free Trade Area (AfCFTA) as the focus of current negotiations, which will result in the adoption of a protocol. The AfCFTA is a significant milestone towards the realisation of the African regional trade agenda, which has a history dating back to 1963 (Desta and Gérout, 2018, p. 113). A detailed overview historical developments will not be repeated here. Suffice it to say that the vision and goal of integration seeded at the very foundations of the AU's predecessor, the Organisation of African Unity (OAU) is coming to fruition. Significant milestones include the Agreement establishing the AfCFTA (AfCFTA Agreement)'s entry into force on 30 May 2019 [1] and the start of trading under the agreement on 1 January 2021 (AU, 2020a). Article 7 of the AfCFTA Agreement provides for the conclusion of Phase 2 negotiations on IP rights (IPRs) and investment competition policy. Since the conclusion of the AfCFTA Agreement, the AU resolved to add e-commerce to another round of negotiations, which together with the Phase 2 negotiations should be completed by 31 December 2021 (AU, 2020b). Indeed, because the agreement is member-driven, one may envisage the conclusion of further instruments as determined by AU member states in the future. There are already strong indications that a Protocol on Women, Youth and SMEs will be negotiated next (Erasmus, 2021). Article 8 states that the further negotiation legal texts, once concluded, will augment the Agreement by "upon adoption, form[ing] an integral part" of the Agreement and becoming "part of the single undertaking, subject to entry into force". The formula for entry into force is set out in Article 23 as follows:

- "The Protocols on Investment, Intellectual Property Rights, Competition Policy and any other Instrument within the scope of this Agreement deemed necessary, shall enter into force thirty (30) days after the deposit of the twenty second (22nd) instrument of ratification" (para 2).

- "For Member States acceding to the Protocols on Investment, Intellectual Property Rights, Competition Policy, and any other Instrument within the scope of this Agreement deemed necessary, shall enter into force on the date of the deposit of its instrument of accession" (para 4).

Beyond the above, the AfCFTA Agreement contains minimal provisions on IP. Article 4(c) states that the state parties "shall cooperate" on IPRs. Clearly, the protocol on IPRs (hereafter IP protocol) will provide the requisite details on the nature of that co-operation and will have a significant impact on the regulation of IPRs on the African continent within the context of intra-Africa trade. Therefore, it is worthy of scholarly commentary.

This paper will proceed by discussing the form and general nature of AfCFTA Agreement Protocols to give insight into what shape the IP protocol may take in Section 2. Section 3 will focus on the possible provisions of the IP protocol. It will include subsections on the various parts to be included in the protocol and such discussion will include some commentary on the process to be followed in the negotiation. In this respect, it will refer to experiences gleaned from the negotiation of other trade agreements to ascertain which lessons can be drawn for the AfCFTA IP protocol. It is important to stress the importance of mainstreaming gender considerations into the discussion of the AfCFTA Agreement and its protocols, which are an integral part of it. The rationale for paying special attention to women, along with youth and small and medium sized enterprises (SMEs) is that they form the core of the continent's economically active population and are the drivers of trade, both within national borders and across borders. Oft-quoted statistics are that women account for " $70 \%$ of informal cross border traders" and SMEs constitute "80\% of the region's businesses" (Luke, 2019, p. 9). Africa is a 
youthful continent, with the majority of the population being under the age of 25. Therefore, much effort is expended in addressing the needs and concerns of these constituencies, for instance, through the AU Strategy for Gender Equality and Women's Empowerment (GEWE) (2018-2028). Further, significant work is being undertaken to demonstrate how the AfCFTA can be harnessed for them (AfCFTA and UNDP,2020). As stated above, a protocol on women, youth and SMEs may soon be negotiated (Erasmus, 2021). However, that probability does not remove the imperative to consider gender, youth and SMEs during the negotiations of the IP protocol. These would remain centred in the considerations of substantive IP matters to be addressed. Accordingly, Section 3.3.1 will highlight some of the pertinent gender issues. Then, the paper will consider the possible scope of IP matters that could be addressed in the IP protocol in Sections 3.3.2 and 3.3.3. These are largely informed by the IP agenda established within the context of the COMESA-EAC-SADC Tripartite Free Trade Area (TFTA)'s pending phase II negotiations. The paper notes that the IP protocol will not expressly provide IP protection provisions that apply only to women; its point is that the inclusion of areas that are of relevance to women, for instance PVR and PBR, will benefit them as the statistics show that they are more concentrated in entrepreneurial activities that would benefit from these provisions. Provisions on technical assistance and capacity building as well as institutional provisions will also be discussed in Sections 3.4 and 3.5. The technical co-operation and capacity-building provisions ought to include specific interventions that seek to address the gendered challenges identified in the paper. Section 4 will conclude with a summary of the recommendations made in the paper.

\section{African Continental Free Trade Area protocols - a template for the IP protocol}

The AfCFTA Agreement currently consists of protocols on Trade; Goods and Services; and Rules and Procedures on the Settlement of Disputes. Scrutiny of these existing protocols gives insight into the probable form of the IP protocol; in other words, one can see which clauses are likely to have an equivalent in the IP protocol. These elements are all present in the three existing protocols. They are as follows:

(1) A preamble;

(2) Definitions, objectives and scope;

(3) Non-discrimination or General Obligations and Principles (e.g. Most-FavouredNation Treatment, National Treatment);

(4) Subject area-specific provisions;

(5) Technical Assistance, Capacity Building and Cooperation; and

(6) Institutional Provisions (Consultation and Dispute Settlement, Implementation, Monitoring and Evaluation, Amendment).

It is customary to arrange these elements into parts, as appropriate. For instance, the AfCFTA Agreement's 30 articles are arranged into seven parts and the Protocol on Goods' 32 articles are divided into ten parts. The number of sections and parts is one of form, and not one that requires any further discussion. It is sufficient to reiterate that the IP protocol will follow the template established in the AfCFTA Agreement and other protocols. It is important to pay attention in this manner to the form or shape that the IP protocol will take to manage expectations by reiterating that the protocol is part of the AfCFTA Agreement package and will accordingly conform to existing templates. With the shape and form, so described, one may proceed to consider the substantive aspects that can, and ought to be, 
JITLP 21,2

addressed in the IP protocol. One can comment on what ought to be addressed in each of the IP parts with a reasonable measure of certainty based on what research and experience has taught about IP on the continent. These aspects will be addressed in detail in the following subsections.

\section{Intellectual property protocol provisions}

This part will discuss some of the substantive aspects that can reasonably be expected to be addressed by the protocol, given their significance to Africa.

\subsection{Preamble}

First, the preamble needs to strike an appropriate tone with regard to the developmental priorities on the continent and the needs of citizenry. The failure to include an appropriately nuanced preamble was one of the key criticisms about earlier drafts of the Statute of the Pan-African IP Organisation (PAIPO Statute), which, five years after its adoption in 2016, is yet to come into force. Specifically, it was argued that the preamble in that early draft referenced 'socio-economic development and effective IP systems. However, it does not go far enough in affirming the perspectives on IP and development' which were advanced by African states themselves at international norm-setting forums (Ncube and Laltaika, 2013, p. 116). It was recommended that the draft preamble ought to be revised to include language referencing the public interest considerations as articulated in Articles 7 and 8(1) of the Agreement on Trade Related Aspects of Intellectual Property Rights (TRIPS Agreement). Further, it was suggested that there was a need for express wording to consolidate the positions taken in key decisions pertaining to public health, which include the 2001 Declaration on the TRIPS Agreement and Public Health ("Doha Declaration"). Eventually, the draft was revised and the final PAIPO Statute now includes some phrases that meet some of the above concerns. This text goes some way in addressing some development concerns but still shies away from expressly referencing public health declarations. Accordingly, based on this experience, the IP protocol's preamble ought to reference key IP instruments particularly those that directly address the continent's priorities. Specifically, in view of the continent's experience during the COVID-19 pandemic, at a bare minimum, it would be necessary to reference public health-related IP instruments. This recommendation would extend to the TRIPS amendment introducing art 31 bis which came into force on 23 January 2017 for accepting member states which, as at October 2020, included 26 African states (Ncube, 2021, p. 54). Numerically, they represent almost 50\% of AU membership and therefore signify significant agreement of the importance of the TRIPS amendment.

\subsection{Definitions, scope, objectives and principles}

The definition section will cover key IP-related definitions. There would be no need to repeat definitions already provided for in the AfCFTA Agreement so this part of the IP protocol would only contain definitions which are pertinent to IP. These would include definitions of IP, the different IPRs and the African IP organisations. It is important to note that these are settled concepts and the definitions can therefore be taken or quoted from existing instruments such as the TRIPS Agreement and the AU's PAIPO Statute. In addition, the regional IP organisations, African Regional Intellectual Property Organisation (ARIPO) and the African Intellectual Property Organisation/Organisation Africaine de la Propriété Intellectuelle (OAPI) already have several instruments from which definitions can be sourced.

The scope of the protocol would be limited to IP matters and the article on objectives would draw from both the general objectives of the AfCFTA Agreement stated in Article 3 
(b) and the IP-specific objective in Article 4(c) which is for AU member states to cooperate in IP. The latter objective, like the others in Article 4 is, in effect, a "specific measure" to realise the general objectives listed in Article 3 (Akinkugbe, 2020, p. 142). Similarly, the articles on fundamental principles would be grounded in Article 5 of the AfCFTA Agreement which lists ten principles. These are:

a. driven by Member States of the AU;

b. RECs' Free Trade Areas (FTAs) as building blocs for the AfCFTA;

c. variable geometry;

d. flexibility and special and differential treatment;

e. transparency and disclosure of information;

f. preservation of the acquis;

g. Most-Favoured-Nation (MFN) Treatment;

h. National Treatment;

i. reciprocity;

j. substantial liberalisation;

k. consensus in decision-making; and

1. best practices in the RECs, in the State Parties and International Conventions binding the AU.

These principles are common to other trade agreements and are found in Article 6 of the TFTA Agreement and explained in the modalities for negotiation (COMESA, EAC, SADC, 2018). These explanations are applicable to the AfCFTA agreement and each has been discussed in detail by other scholars elsewhere (Desta and Gérout, 2018, p. 137). For illustrative purposes, this section will only summarise and comment on the first eight principles (paras (a)-(h)). In brief, their import is that AU member states will determine the nature and implementation of the AfCFTA Agreement, whilst consolidating and drawing from progress already made by the Regional Economic Communities (RECs) towards trade liberalisation and integration [paras (a) and (b)]. This is closely related to the principle of preservation of the acquis [para. (f)], which means working from the foundation of gains already made and, where achievable, improving or bettering them. However, as noted by Desta and Gérout, this is more easily said than done because a technical scrutiny of the actual position of RECs' liberalisation shows that the TFTA would not be able to preserve the REC acquis (Desta and Gérout, 2018, p. 132). The variable geometry principle [para (c)] means that the negotiation and implementation of the AfCFTA will provide leeway and policy space for member states to progress at different speeds in view of their socioeconomic context; to provide means to reduce "distributional losses" and grant certain preferences to eligible states (Gathii, 2011, p. 35). Again, it has been noted that this principle complicates the TFTA, and by extension, the AfCFTA because it enables different standards to be simultaneously in place (Desta and Gérout, 2018 p. 133). Further, states with unique "trade needs, specificities and circumstances" will be granted flexibility and special and differential (S\&D) treatment will "apply to flexibilities in transitional periods for liberalization, exemptions as well as other measures within [...] negotiations applicable to Member/Partner States at different levels of socio-economic development" (COMESA, EAC, SADC, 2018, p. 7). As noted by others, S\&D treatment is an accepted and common feature of trade agreements, even in relation to IP (Kuhlmann and Agutu, 2020, p. 764). The TRIPS Agreement provides for transition periods for least developed countries (LDCs), which, in 
JITLP 21,2

effect, places different obligations on countries at different levels of development by granting LDCs a "grace period" during which they do not have to comply with the whole of the agreement. Article 66.1 of the TRIPS Agreement provided for an initial transition period up to 2006. This period has been extended several times and will now run until 1 July 2034, or earlier should the LDC become a developing country before that date (WTO TRIPS Council 2021a, 2021b). There is a further transition period in relation to pharmaceuticals that is in place until 1 January 2033 or earlier should the LDC cease to be an LDC before that date (WTO TRIPS Council, 2015). In terms of this transition period, LDCs are not required to give exclusive marketing rights to pharmaceuticals that are subject of a patent application as is provided for in Article 70.9 of the TRIPS Agreement. Therefore, LDCs currently have the policy space to make unique IP regimes that are appropriate to their socio-economic development during these extendable transition periods.

Negotiations are to be conducted in a "transparent manner" supported by the adequate sharing of relevant information, without any compulsion to disclose confidential information [para (e)]. This is a very important aspect that has informed all AfCFTA negotiations thus far and which is expected to continue into the Phase 2 negotiations, in accordance with the AU Statement of the Objectives and Guiding Principles for Negotiating the Continental Free Trade Area. As noted elsewhere, the failure to ensure transparency and meaningful consultation has scuppered the IP chapters of several trade agreements (Ncube et al., 2019, pp. 177-178). Further, specific principles for IP provisions in bilateral and regional trade agreements have been developed (Grosse Ruse-Khan et al., 2013), which can and must be adapted for use in the AfCFTA context.

There would be no need to repeat all of the above principles provided for in Article 5 of the AfCFTA Agreement in the IP protocol and all that would be necessary is an articulation of those principles that have a specific IP connotation. This is the approach taken in the existing protocols. For instance, the Protocol on Goods' Article 5 provides for MFN treatment and Article 6 provides for National Treatment. In the context of IP, these principles are articulated in the TRIPS Agreement in Articles 3 (National Treatment) and 4 (MFN). Therefore, the IP protocol's clauses on these principles would, of necessity, crossrefer to the TRIPS Agreement. This would mitigate the difficulties that have been identified with regard to these principles in Article 5, principally that their combination with the principle of reciprocity serves to negate the MFN principle. In Desta and Gerout's words, "whatever benefits a country may acquire cannot be the same as those enjoyed by the partner that is most favored; on the contrary, they will be as good or as bad as the TFTA country's ability to "pay for" them, i.e. by their ability to reciprocate" (2018, p. 134). There is a significant body of scholarship on the meaning of MFN and National Treatment in the context of IP rights which would then be applicable to the protocol pursuant to the crossreference to the relevant TRIPS Agreement articles.

After this part of the IP protocol dealing with scope, objectives and principles, the rest of the protocol would be informed by the principles, as would the interpretation of its provisions. Following this, a significant portion of the protocol would address IP-specific issues which are discussed below.

\subsection{Substantive intellectual property provisions}

As argued elsewhere, the substantive provisions of the IP protocol need to be principled, that is based on sound principles (Ncube et al., 2019). There are several sources of such principles, identified in Section 3.2, namely, article of the AfCFTA Agreement, the AU Statement of the Objectives and Guiding Principles for Negotiating the Continental Free Trade Area and suitably nuanced internationally developed principles for IP provisions in 
bilateral and regional trade agreements. From this foundation, this section discusses specific IP matters that ought to be addressed in the IP protocol. It is divided into three parts, with the first briefly sets out the gender dimensions of IP, the second reprises the IP issues identified for inclusion in the TFTA Phase II negotiations and the third briefly considers some of these issues.

3.3.1 Introduction to the gender dimensions of intellectual property. The rest of this section's overview of specific IP aspects must be understood in a way that remains alert to gendered challenges, or the "IP gender gap". IP laws and policies often appear gender neutral because they do not expressly address gender. However, informed by GEWE (2018 2028 ) it is critical that IP protocol negotiators note existing gender inequalities because IP laws and policies are made in environments that have structural gender inequalities, including in access to land and property rights as well as access to technology (Randriamaro, 2008). These inequalities have detrimental effects on women farmers and entrepreneurs through reduced access to seeds, farm inputs and plants, which may be exacerbated by IP laws that fail to give proper protection to their agricultural products or restrict their access to knowledge and resources that would enable them to be productive. Here the focus would be on plant breeders' rights (PBR) and the protection of plant varieties (PVP). Section 3.3.3 discusses the options available in relation to provisions on PBR and PVP at paragraph 5, where it is noted that such provisions would be beneficial to women given the disadvantages highlighted here. Further, women face significant hurdles in obtaining IP protection for their goods and services, in relation to (a) those easily protected by IP rights such as patents and trademarks and (b) those that are based on traditional knowledge (TK) which is not so readily accommodated by existing IP rights. With regard to Category (a), studies have shown that there are less women inventors listed on patents (WIP0, 2021) and more patents are owned by men than women (UK Intellectual Property Office, 2019). Similar findings have been made with regard to design rights, utility model and trademarks (Heikkilä, 2018). For Category (b), the existing problems in relation to the proper protection of TK have a more marked impact on women because they tend to create most works that fall into this category, as shown by recent research in South Africa (Oriakhogba, 2020, p. 146; Oriakhogba and Musiza, 2018).

As indicated in Section 1, women constitute the bulk of informal cross-border traders; therefore, any disadvantages accruing to small businesses ultimately affect them. It has already been established that small businesses in the informal sector have little awareness and knowledge of IP. Add to this the structural inequalities that blight women's access to education and financial resources, and it becomes evident that this will result in a significant portion of women entrepreneurs not knowing about IP rights and how to use them effectively; lacking the resources to navigate the administrative complexity and costs associated with registering IP rights; and in some contexts, having difficulties in accessing IP offices which tend to be located in central business districts in urban areas. All of these challenges will be multiplied when women trade in several national markets primarily because IP regulation is national and, while there is some harmonisation of minimum standards, there is great variance across the continent and globally. Women in business who trade across borders therefore need to navigate multiple national IP systems whilst bearing some of the disadvantages highlighted above. The suggested provisions offered in Section 3.4 on co-operation to empower and educate entrepreneurs will go a significant way towards meeting these challenges, more so when the interventions are targeted at women.

3.3.2 Tripartite Free Trade Area intellectual property agenda. The AfCFTA vision is one of consolidation, rather than one of starting afresh. Further, the RECs are building blocks and therefore their existing initiatives will be on-boarded, rather than discarded. 
JITLP 21,2

Therefore, it is important to recall that the RECs, within the context of the TFTA, had already identified the following aspects for inclusion in their Phase II IP negotiations (Ncube, 2021, pp. 87-88; UNECA, AU, AfDB and UNCTAD, 2019, p. 109):

- whether a regional IP exhaustion regime should be adopted, together with an undertaking for member states to accept the TRIPS amendment so that a regional mechanism for re-exportation of products produced or imported under a compulsory license within the regional market can be established and implemented;

- crafting a Tripartite regional policy, akin to the EAC Regional IP TRIPS Flexibilities Policy and to consider whether an endorsement of the Nairobi Statement on Investment in Access to Medicines, or a similar commitment would be appropriate;

- creating a regional PBR regime that can co-exist with membership of UPOV (1991) by OAPI member states, Kenya, Morocco, Tunisia and Tanzania;

- deliberating on whether a collective commitment should be made for all partner states to ratify the Marrakesh Treaty to Facilitate Access to Published Works for Persons Who Are Blind, Visually Impaired or Otherwise Print Disabled (Marrakesh Treaty);

- deliberating on whether there ought to be a commitment for a mandatory disclosure requirement regarding the use of genetic resources and associated TK in patent and PBR laws;

- whether there should be a Tripartite agreement or position to the effect that WHO Framework Convention on Tobacco Control related measures do not constitute an expropriation of IP nor an infringement of IP rights; and

- Whether there should be a commitment and mechanism for patent examination cooperation.

These agenda items are discussed below with a view to ascertaining whether they should be adopted, as is or with some adjustments, in the AfCFTA IP negotiations.

3.3.3 Discussion of some aspects of the Tripartite Free Trade Area and African Continental Free Trade Area intellectual property agenda. The first and most important point to emphasise is that IP is already comprehensively regulated on the continent because there are:

- binding international agreements which many African states are party to;

- there are binding sub-regional IP agreements from the regional IP organisations; some policies and guidelines from some RECs and a few AU instruments both binding and non-binding; and

- all states have national IP laws supported by relevant institutions that register IP rights.

These layers of IP regulation have been fully listed and discussed elsewhere (Ncube, 2021, pp. 29-89; UNECA, AU, AfDB and UNCTAD, 2019; UNECA, 2017, 2016, 2006; Ncube, 2016), so they will not be discussed here. It will serve present purposes to indicate that there are two sub-regional IP organisations, namely, ARIPO [2] and OAPI [3]. ARIPO uses a harmonisation model through which Member States elect which protocols to join. They retain their national IP laws and offices. It is possible to apply for some rights through the ARIPO system and to designate some or all ARIPO Member States for the registration 
rights. OAPI has a unitary system with a uniform legislation, a common office and centralised procedures which grant IP rights over the entire OAPI territory.

In view of all this existing regulation, the IP protocol does not have to seek to regulate all aspects of IP. In any event, its stated mandate is to provide for co-operation in IP which is different from regulation in IP. National IP laws and the statutes of all existing IP institutions at continental and regional levels, such as the PAIPO Statute and the regulatory instruments of RECs, ARIPO and OAPI, will continue to form the bedrock of regulation whilst the IP protocol will focus on co-operation. It should only seek to attend matters that Intellectual property are either not covered at all or are inadequately covered by existing regulation. The consideration of existing regulation would also seek to identify where there is disharmony at the regional and sub-regional levels. The logical starting place of such consideration would be, with the most significant binding international agreement, the TRIPS Agreement. Beyond the TRIPS Agreement, there are at least 35 other international agreements regulating IP to which two or more AU member states are parties (De Beer et al., 2018). This section will focus on the TRIPS Agreement because of its primacy and significance. However, as influential as it is, it is also important to note that not all AU member states are bound by the TRIPS Agreement because they are not members of the WTO. It is therefore necessary to incorporate TRIPS Agreement standards by reference into the IP protocol.

The TRIPS Agreement sets minimum standards for the protection of IP rights and their enforcement. In some instances, it leaves policy space for WTO member states to determine an appropriate approach for their developmental context, as long as the agreed minimum standards are met. Some of the RECs have moved into this space by providing some policy guidelines on how to best leverage this policy space in relation to public health related flexibilities. Similarly, other international agreements regulating IP rights typically leave some policy space to party states to create national IP laws that correspond to their development priority needs, provided that they respect the international minimum standards established under the relevant agreement. This means that the IP protocol could have a role in giving direction on how AU member states may wish to use their policy space in crafting national laws. This would enhance co-operation on IP matters by enabling harmonious approaches. Hence, the identification of the possibility of a regional TRIPS Flexibilities Policy informed by the EAC's policy (Item 2 on the TFTA IP negotiations list).

In other cases, the TRIPS Agreement does not regulate certain aspects at all, leaving them entirely at the discretion of WTO member states. This is the case regarding the policy space relating to exhaustion of intellectual property regimes, which Article 6 of the TRIPS Agreement leaves at the discretion of the member states. The concept of exhaustion of IP rights essentially entails that the right holder's control over the IP protected product (in relation to patents and copyright, as an example) expires after the entry of that item onto the market (sometimes referred to as "first sale") at either international, regional or national level depending on the type of exhaustion applicable in the country where the IP right is valid. The underlying IP right is not lost upon entry into the market, so in this example the relevant patent or copyright will subsist until it expires in accordance with the law. What lapses, expires or is exhausted is the right holder's control over further distribution of the physical object, such as the book protected by copyright or the pharmaceutical product protected by the patent. Where international exhaustion applies, the IP right holder's control over further distribution lapses once the item or product is sold or otherwise introduced into the market, anywhere in the world. Where regional exhaustion applies, it lapses upon the item's entry into a regional market and where national exhaustion applies, it only lapses when the first sale is made in that national market, in other words the IP right holder must introduce the item into either the regional or national market before others can distribute it 
JITLP 21,2

\section{4}

further. The most restrictive of these approaches is the national exhaustion principle and the most open is the international exhaustion principle. The significance of these approaches is best illustrated by an example in the public health context. Where a state uses the regional approach, it can procure supplies such as medicines and medical devices from others markets in a defined region such as the AU, and where it subscribes to international exhaustion, then it can procure them from any market. This is a critical flexibility because it would allow AU member states to collaborate to enable the procurement of pharmaceuticals and medical devices to parallel import these supplies. Hence, the suggestion for the consideration of a regional IP rights together with AU member states' acceptance of the TRIPS amendment (introducing Article 31 bis) so that it would be possible to craft a mechanism for reexportation of products produced or imported under a compulsory license within the regional market (Item 1 on the TFTA IP negotiations list). As noted above, 26 AU member states have already accepted the amendment. Further, several already subscribe to either regional or international exhaustion principles. For example, South Africa provides for parallel importation in s15C of its Medicines and Related Substances Act 101 of 1965. Finally, it is important to note that negotiations on these aspects would be informed by discussions at the TRIPS Council on the proposal for a TRIPS waiver proposed by India and South Africa in 2020 (WTO TRIPS Council, 2020), as revised in 2021 (WTO TRIPS Council, 2021a, 2021b), which has since garnered wide support, including by the AU itself (AU (2021). Therefore, whatever outcomes are reached should be in keeping with this position.

A further example is how the TRIPS Agreement does not detail PVP and PBR which are very significant for Africa's agriculturally based economies which support many farmers who depend on traditional farming practices and the seed industry. It requires countries to provide an effective level of protection either through patent protection or a system created specifically for the purpose (sui generis), or a combination of the two. This means that party states have an option regarding such protection and may be guided by the IP protocol in this regard if they have not already signed onto a particular form of protection. Exercising this option, some AU member states have become party to the International Convention for the Protection of New Varieties of Plants (UPOV Convention) of 2 December 1961, as revised on 19 March 1991 (UPOV 1991) and ARIPO and SADC have adopted protocols based on UPOV 1991 although they have not yet come into force. The states that are members of UPOV 91 are OAPI member states, Kenya, Morocco, Tunisia and Tanzania, while South Africa subscribes to UPOV 1978 (UPOV, 2021). These developments have generated a lot of debate and discussion (De Jonge and Munyi, 2016; Oguamanam, 2015). Practically, they mean that harmonisation and co-operation in this area have to take into account these existing commitments. This is reflected in the TFTA IP negotiations list (Item 3). In pursuing this item, it will be important to remember that the AU has a non-binding model law which includes PBR which countries may use to draft national laws (Feris (2004). Given that women are heavily represented in agricultural related trade, paying attention to this aspect would contribute to efforts to ensure a better trade deal for women.

Another important aspect is the protection of TK and traditional cultural expressions (TCEs). Many SMEs in Africa trade in TK- and TCE-related goods and services. The protection in the TRIPS Agreement, specifically copyright, patent, designs and trademarks, does not always cover them because they do not meet protection requirements. For example, because they are usually known in a community for generations, they are not "new" for patent purposes and they are also not "original" and captured in a material form (e.g. written or recorded) for copyright purposes. That is why there are continuing discussions about suitable protection at WIPO's (2021) Intergovernmental Committee on IP and Genetic Resources, Traditional Knowledge and Folklore (IGC) and why ARIPO has the 
Swakopmund protocol to provide unique protection for them. Several African countries also have sui generis laws. For example, Kenya's Protection of Traditional Knowledge and Cultural Expressions Act, No. 33 of 2016; Zambia's Protection of Traditional Knowledge, Genetic Resources and Expressions of Folklore Act, No. 16 of 2016; and South Africa's Protection, Promotion, Development and Management of IK Systems Act, Act 6 of 2019.

The TFTA IP Agenda has a rather limited view of how to engage with this aspect. It is restricted to whether the negotiating parties should agree on a mandatory disclosure requirement for the use of genetic resources and associated TK in patent and PBR laws. This is a requirement coming from the Convention on Biological Diversity (CBD) and the Nagoya Protocol on Access to Genetic Resources and the Fair and Equitable Sharing of Benefits Arising from their Utilization to the Convention on Biological Diversity (Nagoya protocol) and the International Treaty on Genetic Resources for Food and Agriculture (ITPGRFA), which is already met in several states' patent laws. It is recommended that the AfCFTA IP negotiations take a broader and more comprehensive approach to the protection of TK than that indicated in the TFTA IP agenda. To this end, there are already national sui generis laws to learn from as well as the ARIPO Swakopmund Protocol and the AU Model Law.

Recommendations have been made elsewhere about specific IP rights including copyright, trademarks, and patents (Ncube et al., 2019, p. 185). The TFTA IP negotiation items list takes a rather restrictive view, and is limited to the following aspects only:

- for copyright to a deliberation of whether there should be provision on the ratification of the Marrakesh Treaty;

- for trade marks to consider whether plain packaging for tobacco products would amount to expropriation of IP or an infringement of IP rights; and

- for patents to discuss cooperation in patent examination.

A broader view of each of these IP rights would entail aspects such as:

- Copyright: A commitment to ensuring the availability of exceptions and limitations for other disabilities, educational use, temporary copies, parallel importation; orphan works and text and data mining (Ncube et al., 2019, p. 185). The large-scale shift to online and distance teaching and learning in 2020 forced by physical distancing regulations and lockdowns to curb the spread of COVID-19 demonstrated the inadequacy of existing exceptions and limitations for educational use and online environments.

- Trademarks and geographical indications (GIs): Consideration of more appropriate forms of marks in use on the continent would need to extend to better use of GIs which will be informed by the AU GI Strategy. An analysis of how, if at all, existing trademark protection could be harmonised could also be undertaken because some trademark duration variances exist on the continent.

- Patents: The COVID-19 pandemic and its related health care needs emphasised the need for appropriately nuanced patent systems and their implementation. It further showed the inadequacies of some existing statutory provisions such as those for compulsory licenses. Much attention, therefore, needs to be paid to patent law reform and to cooperation between AU member states during pandemics and other emergencies.

In summary, the list of IP negotiation priorities identified for the TFTA are a credible starting point for the AfCFTA IP protocol, albeit with the broadening of the scope of some aspects as indicated above. 
JITLP

21,2

116

\subsection{Technical assistance, capacity building and cooperation}

Following the format of other protocols, the IP protocol will have provisions on technical assistance, capacity building and cooperation. In view of the stated objective in Article 4 of the AfCFTA Agreement, this is indeed the heart of the IP protocol. Therefore, it will be important to expressly state the scope of this cooperation, which may include supporting industrialisation, fostering trade amongst $\mathrm{AU}$ member states and development in accordance with Agenda 2063 and STISA.

Thereafter, specific measures would need to be stated. For example, cooperation in patent examination has already been flagged by the TFTA states, so one would expect to see it here. Such a provision ought to be accompanied by a series of other interventions generally intended to enhance IP administration capacity on the continent. These would include information sharing on best practices, collaboration in training initiatives and capacity building in relation to systems through automation, for example. Similarly, the need to harmonise IP laws, where possible, would be expected here as it has been identified as a possible area of attention in Section 3.3. Other aspects highlighted in that section would, of necessity, appear here. For example, because GIs were identified as being particularly relevant and there is already an AU Strategy on this, a provision on cooperation on the promotion of the creation of regulatory frameworks to enable and support the use of geographical indications, collective marks and certification marks would be needed.

Cooperation measures should also be specifically directed towards overcoming some of the gendered challenges identified in Section 3.3.1. For example, IP awareness campaigns should be as inclusive as possible to ensure that they reach women, youth and SMEs. Such campaigns would seek to deliver the required knowledge about IP rights within different national territories; how to register IP rights (e.g. how to use ARIPO, OAPI and WIPO systems to apply for rights); and how to enforce them. Other examples would be for AU member states to cooperate in:

- addressing how to bring services and expertise closer to enterprises that are not in central business districts;

- providing financial assistance and expertise to apply for the registration of IP rights; and

- offering administrative support for enterprises or introducing streamlined and simpler processes.

When considering co-operation, it is important to note and include all the existing role players, namely, national IP offices, ARIPO, OAPI, the RECs and, once it is operational, PAIPO. The IP registration mandate of national IP offices, ARIPO and OAPI already provides comprehensive registry infrastructure and what remains is to build capacity evenly across the continent. The policy influence roles of the RECs and PAIPO would also require coordination and coherence. Such an approach will avoid duplication and ensure that resources and capacity are used efficiently.

\subsection{Institutional provisions}

Finally, in keeping with other protocols' structure, there would be provisions on the body or grouping within the AfCFTA infrastructure that is responsible for IP matters.

Article 9 of the AfCFTA Agreement provides that:

"The institutional framework for the implementation, administration, facilitation, monitoring and evaluation of the AfCFTA shall consist of the following:

- the Assembly;

- the Council of Ministers; 
- the Committee of Senior Trade Officials; and

Intellectual

- the Secretariat."

Article 11 provides that the Council of Ministers, which will comprise "Ministers responsible for Trade or such other ministers, authorities, or officials", as selected by AU member states will have oversight of the implementation of the Agreement. This article provides extensive detail on the mandate and working of the Council of Ministers, of particular interest to this chapter is Article 11(3)(f) which states that it may "establish and delegate responsibilities to ad hoc or standing committees, working groups or expert groups." Therefore, there will be a Committee on IP. Accordingly, the institutional provisions in the IP protocol will detail the composition and the workings of the committee. As noted above, the IP protocol will be entering a pre-existing continental, regional and national IP regulatory infrastructure that consists of the yet to be operationalised PAIPO, ARIPO, OAPI and the RECs which have IP policies and instruments such as the TFTA IP agenda which has been discussed in Section 3.3.2 and national IP institutions. The roles of each of these are clear and do not overlap with the AfCFTA Secretariat and the Committee on IP. For instance, ARIPO, OAPI and national IP offices will continue to implement their regulatory instruments and to register IP rights. Therefore, these pre-existing institutions must be factored into the Committee on IP through appropriate integration and representation. Accordingly, representative of AU member states, RECs, ARIPO and OAPI would be expected to be members of the IP Committee. Similarly, when PAIPO is operationalised, it would be represented on the Committee on IP.

\section{Concluding remarks and recommendations for the African Continental Free Trade Area intellectual property protocol negotiators}

This paper has explained the probable structure and format of the IP protocol, which will be in keeping with the AfCFTA and its other protocols. It then proceeded to consider what one would then expect to encounter in each of the IP protocol's parts, paying attention to important issues or aspects to include. For example, the preamble would need to highlight Africa's developmental priorities and the principles section would, of necessity, refer to the National Treatment and MFN principles as articulated in the TRIPS Agreement. This chapter has argued that a robust and relevant approach needs to be taken to the content of the IP protocol's IP-specific provisions in view of the significant opportunity they present to consolidate gains made so far and to chart a path for IP that better serves the continent and all its traders, including large corporate entities, SMEs, women and youth. IP is already heavily regulated and all AU member states have laws and institutions informed by their obligations under international treaties, other agreements such as bilateral trade agreements and IP instruments they are party to either through ARIPO, OAPI and some of the RECs. Therefore, to speak metaphorically, there is no need to reinvent the wheel, rather the wheel should be examined for punctures, structural damage and alignment so that necessary repair, modifications and re-alignment can be done.

To this end, the paper began by highlighting some specific aspects which are of importance to all traders, but which are markedly significant for women, considering the structural and personal disadvantages affecting a high portion of women traders and which are amplified in cross border contexts. The specific matters that need addressing are well identified in the TFTA IP agenda, which should be used as a starting point. Indeed, given that the TFTA second-phase IP negotiations are yet to start, it would be prudent to coalesce them with the AfCFTA's. Even where that is not done, the TFTA IP agenda remains a credible point of departure, albeit with the necessary expansions as summarised below. 
JITLP 21,2

\section{8}

In that regard, the chapter contended that the IP protocol ought to contain provisions on the following:

- IP and health-related aspects: The uptake of TFTA vision for the adoption of a regional IP exhaustion regime by contracting states, plus a commitment to accept, domesticate and implement the TRIPS amendment by those states that have not done so, to enable the creation of a regional mechanism for import and regional exportation of needed healthcare supplies, which is a high priority, given the current dire context. However, because it is evident that current TRIPS flexibilities are not adequate to meet the current challenge and those raised by future pandemics, some thought needs to be given to a more durable continental approach which can be achieved through provisions on co-operation during pandemics and emergencies. In addition to this, the TFTA agenda item on crafting a Tripartite regional policy, akin to the EAC Regional IP TRIPS Flexibilities Policy, and the considerations of an endorsement of a commitment on investment on access to medicines are also apt. Further, the TFTA's agenda item on co-operation in patent examination can also be considered as part of this broad category. Finally, the negotiations on these aspects have to align to the position taken by the AU at the TRIPS Council in relation to the TRIPS waiver proposal that the AU assembly resolved to support in February 2021.

- PBR and PVP: Pursuing the TFTA IP agenda item on creating a regional PBR regime that co-exists with existing UPOV 91 membership on the continent is also worthy of attention.

- Copyright and related rights: The TFTA IP agenda item on a collective commitment to the ratification of accession to the Marrakesh Treaty should be taken up. Implementation would be greatly enhanced by the ARIPO Guidelines on implementing the treaty. However, the AfCFTA IP protocol negotiations should go further than this by considering a commitment to ensuring the availability of exceptions and limitations for other disabilities, educational use, temporary copies, parallel importation; orphan works; and text and data mining. As noted above, the large-scale shift to online and distance teaching and learning along with for all other economic activities in 2020 forced by physical distancing regulations and lockdowns to curb the spread of COVID-19 demonstrated the inadequacy of existing exceptions and limitations for online and distance educational use and online economic activities.

- TK and TCEs: The TFTA IP agenda is limited to negotiating a commitment for a mandatory disclosure requirement regarding the use of genetic resources and associated TK in patent and PBR laws. This is a very narrow way of addressing TK and TCEs which would benefit from expansion, given their importance to a significant section of economic activity in the creative, agricultural, tourism and other sectors. To this end, there are already national sui generis laws to learn from as well as the ARIPO Swakopmund Protocol and the AU Model Law that may better inform a continental perspective.

- Trademarks: The TFTA IP agenda is limited to discussion of whether there should be a Tripartite agreement or position to the effect that WHO Framework Convention on Tobacco Control related measures do not constitute an expropriation of IP or an infringement of IP rights. This should be broadened to include other aspects such as a consideration of more appropriate forms of marks in use on the continent, namely, collective and certification marks as well as to the use of GIs which will be informed by the AU GI strategy. Finally, an analysis of how, if at all, existing trademark 
protection could be harmonised could also be undertaken because some trademark duration variances exist on the continent followed by a commitment to harmonise to enable even protection of trademarks across the continent.

In closing, engaging with the above substantive IP law issues should dovetail with the IP protocols provisions on technical assistance and co-operation. As is evident from the section on IP and health related aspects, agreement on laws can and should be enhanced by cooperation in patent examination for example. Further supportive areas of cooperation would include information sharing on best practices, collaboration in training initiatives and capacity building in relation to systems through automation of IP offices. Cooperation measures should also be specifically directed towards overcoming some of the identified gendered challenges, so that, for example, IP awareness campaigns should be as inclusive as possible to ensure that they reach women, youth and SMEs. They should also leverage existing institutions and equip traders, especially cross-border traders about IP rights within different national territories; how to register IP rights at national IP offices, ARIPO, OAPI and WIPO systems; and how to enforce them. Other examples of activities that would benefit from co-operation are access to IP services and expertise, financing and administrative support for entrepreneurs. Finally, the best outcomes in both negotiation and eventual implementation of the adopted IP protocol will be achieved by an inclusive approach incorporating national IP offices, ARIPO, OAPI, the RECs and, once it is operational, PAIPO with policy coherence and coordination to preclude duplication, thereby ensuring that resources and capacity are used efficiently.

\section{Notes}

1. AU (2018) Agreement Establishing the African Continental Free Trade Area (AfCFTA Agreement).

2. ARIPO member states: Botswana, eSwatini, Gambia, Ghana, Kenya, Lesotho, Liberia, Malawi, Mozambique, Namibia, Rwanda, Sao Tome \& Principe, Sierra Leone, Somalia, Sudan, Tanzania, Uganda, Zambia and Zimbabwe. Observer states: Angola, Burundi, Egypt, Ethiopia, Eritrea, Mauritius, Nigeria, Seychelles and South Africa.

3. Member states: Benin, Burkina Faso, Cameroon, Central African Republic, Comoros, Congo, Ivory Coast, Gabon, Guinea, Guinea Bissau, Equatorial Guinea, Mali, Mauritania, Niger, Senegal, Chad and Togo.

\section{References}

AfCFTA and UNDP (2020), "Futures report on making the AfCFTA work for women and youth".

Akinkugbe, O.D. (2020), "Dispute settlement under the African continental free trade area agreement: a preliminary assessment", African Journal of International and Comparative Law, Vol. 28 No. Supplement, pp. 138-158.

AU (2021), "Decision on the report on the African Union response on COVID-19 pandemic in Africa", Assembly/AU/5(XXXIV).

AU (2020a), "Decision on the start of trading under the African continental free trade area (AfCFTA); Johannesburg declaration on the start of trading under the agreement establishing the African continental free trade area ext/assembly/AU/decl.1 (XIII)".

AU (2020b), "African Union, 2020. Decision on the African continental free trade area (AfCFTA)", Assembly/AU/Dec.751(XXXIII). 
JITLP 21,2

COMESA, EAC, SADC (2018), "Modalities for the tripartite trade in services negotiations", Annex 1: definitions of the Guiding Principles for the Tripartite Free Trade Area (TFTA) Trade In Services Negotiations Tp/Twg-Tis/08/2019/- Modalities Vers.09.08.2019.

De Beer, J., Baarbé, J. and Ncube, C.B. (2018), "Evolution of Africa's intellectual property treaty ratification landscape", The African Journal of Information and Communication (AJIC), Vol. 22, pp. 53-82.

De Jonge, B. and Munyi, P. (2016), “A differentiated approach to plant variety protection in Africa", The Journal of World Intellectual Property, Vol. 19 Nos 1/2, pp. 28-52.

Desta, M.G. and Gérout, G. (2018), “The challenge of overlapping regional economic communities in Africa: lessons for the continental free trade area from the failures of the tripartite free trade area”, in Yihdego, Z. (Ed.), Ethiopian Yearbook of International Law Springer International Publishing AG, Springer Nature, Cham, pp. 111-141.

Erasmus, G. (2021), "Legal architecture of the AfCFTA", presented at Tralac Annual Conference 2021, Cape Town, 23 July.

Feris, L. (2004), "Protecting traditional knowledge in Africa: considering African approaches", African Human Rights Law Journal, Vol. 4, pp. 242-255.

Gathii, J.T. (2011), African Regional Trade Agreements as Legal Regimes, Cambridge University Press, Cambridge.

Grosse Ruse-Khan, H., Drexl, J., Hilty, R.M., Kur, A., Barkhoum, M., Jaeger, T., Köklü, K., Lamping, M., Nadde-Phlix, S., de Beer, J., Correa, C., Dinwoodie, G., Frankel, S., Flynn, S., Hestermeyer, H., Mercurio, B., Roffe, P., Seuba, X. and Yu, P. (2013), "Principles for intellectual property provisions in bilateral and regional agreements", IIC, Vol. 44, pp. 878-883, available at: https:// doi.org/10.1007/s40319-013-0119-1 (accessed 30 July 2021).

Heikkilä, J. (2018), "IPR gender gaps: a first look at utility model, design right and trademark filings", Scientometrics, Vol. 118 No. 3, pp. 869-883.

Kuhlmann, K. and Agutu, A.L. (2020), "The African continental free trade area: toward a new legal model for trade and development", Geo. J. Int'l L, Vol. 51, pp. 753-803.

Luke, D. (2019), "Making the case for the African continental free trade area”, in Luke, D. and Macleod, J. (Eds), Inclusive Trade in Africa: The African Continental Free Trade Area in Comparative Perspective, Routledge, Abingdon pp. 5-12.

Ncube, C.B. (2021), Science, Technology and Innovation and Intellectual Property: Leveraging Openness for Sustainable Development in Africa, Juta, Cape Town.

Ncube, C.B. (2016), Intellectual Property Policy, Law and Administration in Africa: Exploring Continental and Sub-Regional Co-Operation, Routledge. Abingdon.

Ncube, C.B. and Laltaika, E. (2013), “A new intellectual property organization for Africa?”, Journal of Intellectual Property Law and Practice, Vol. 8 No. 2, pp. 114-117.

Ncube, C.B., Schonwetter, T., de Beer, J. and Oguamanam, C. (2019), "A principled approach to intellectual property rights and innovation in the African continental free trade agreement", in Luke, D. and Macleod, J. (Eds), Inclusive Trade in Africa: The African Continental Free Trade Area in Comparative Perspective, Routledge. Abingdon, pp. 177-194.

Oguamanam, C. (2015), "Breeding apples for oranges: Africa's misplaced priority over plant breeders' rights", The Journal of World Intellectual Property, Vol. 18 No. 5, pp. 165-195.

Oriakhogba, D.O. (2020), "Empowering rural women crafters in KwaZulu-Natal: the dynamics of intellectual property, traditional cultural expressions, innovation and social entrepreneurship", South African Law Journal, Vol. 137, pp. 145-172.

Oriakhogba, D.O. and Musiza, C. (2018), "Emphasising the IP gender gap”, UCT News, 26 April, available at: www.news.uct.ac.za/article/-2018-04-26-emphasising-the-ip-gender-gap (accessed 30 July 2021).

Randriamaro, Z. (2008), “Gender and trade - overview report”, available at: www.wedo.org/wp-content/ uploads/cep-trade-or.pdf (accessed 30 July 2021). 
UK Intellectual Property Office (2019), "Gender profiles in worldwide patenting: an analysis of female inventorship (2019 edition)".

UNECA (2006), Assessing Regional Integration in Africa II: Rationalizing Regional Economic Communities, UNECA, Addis Ababa.

UNECA (2016), Assessing Regional Integration in Africa VII: Innovation, Competitiveness and Regional Integration, UNECA, Addis Ababa.

UNECA (2017), Economic Report on Africa 2017: Urbanization and Industrialization for Africa's Transformation, UNECA, Addis Ababa.

UNECA, AU, AfDB and UNCTAD (2019), "Intellectual property protocol", AU Assessing Regional Integration in Africa ARIA IX: next Steps for the African Continental Free Trade Area, ECA Printing and Publishing Unit, Addis Ababa.

UPOV (2021), "Status in relation to the international union for the protection of new varieties of plants (UPOV) as of 22 February 2021", available at: www.upov.int/export/sites/upov/members/en/pdf/ status.pdf (accessed 30 July 2021).

WIPO (2021), "Gender gap in innovation closing, but progress is slow", WIPO, 08 March, available at: www.wipo.int/women-and-ip/en/news/2021/news_0002.html (accessed 30 July 2021).

WTO TRIPS Council (2015), "Extension of the transition period under article 66.1 for least developed country members decision of the council for TRIPS of 6 November 2015", available at: https:// docs.wto.org/dol2fe/Pages/FE_Search/FE_S_S009-DP.aspx?CatalogueIdList=228924,135697,117294, 75909,77445,11737,50512,1530,12953,20730\&CurrentCatalogueIdIndex=1 (accessed 30 July 2021).

WTO TRIPS Council (2020), "Waiver from certain provisions of the TRIPS agreement for the prevention, containment and treatment of Covid-19 communication from India and South Africa $\mathrm{IP} / \mathrm{C} / \mathrm{W} / 669 "$.

WTO TRIPS Council (2021a), "Extension of the transition period under article 66.1 for least developed country members decision of the council for TRIPS of 29 june 2021", available at https://docs. wto.org/dol2fe/Pages/SS/directdoc.aspx?filename=q:/IP/C/88.pdf\&Open=True (accessed 30 July 2021).

WTO TRIPS Council (2021b), "Waiver from certain provisions of the TRIPS agreement for the prevention, containment and treatment of COVID-19 revised decision text", Communication from the African Group, the Plurinational State of Bolivia, Egypt, Eswatini, Fiji, India, Indonesia, Kenya, The LDC Group, Maldives, Mozambique, Mongolia, Namibia, Pakistan, South Africa, Vanuatu, the Bolivarian Republic of Venezuela and Zimbabwe. IP/C/W/669/Rev.1.

\begin{abstract}
About the author
Professor Caroline B. Ncube is the holder of the Department of Science and Innovation and National Research Foundation South African Research Chair in Intellectual Property, Innovation and Development, housed in the Department of Commercial Law at the Faculty of Law, University of Cape Town. Caroline B. Ncube can be contacted at: caroline.ncube@uct.ac.za
\end{abstract}

For instructions on how to order reprints of this article, please visit our website: www.emeraldgrouppublishing.com/licensing/reprints.htm Or contact us for further details: permissions@emeraldinsight.com 